\title{
The role of shuntography in diagnosis of mechanic complications after implantation of ventriculoperitoneal shunts in patients with idiopathic normal pressure hydrocephalus: a retrospective clinical evaluation
}

\author{
Sergej Rot ${ }^{1} \cdot$ Leonie Goelz ${ }^{2} \cdot$ Holger Arndt $^{2} \cdot$ Pawel Gutowski ${ }^{1,3} \cdot$ Ullrich Meier $^{1} \cdot$ Johannes Lemcke $^{1}$
}

Received: 12 August 2021 / Accepted: 11 October 2021 / Published online: 26 November 2021

(c) The Author(s) 2021, corrected publication 2022

\begin{abstract}
Background Mechanical obstruction of ventriculoperitoneal shunt (VPS) during the first year after shunt implantation is a common complication and is widely described in the literature. In this paper, we evaluated the suitability of the shuntography for the diagnosis of mechanical complications of the VPS in patients with idiopathic normal pressure hydrocephalus (iNPH). Methods We retrospectively identified 49 patients with pathologic shuntography over of a period of 20 years in our hospital. The percentage of procedure-associated complications was determined.

Results Ninety-eight percent $(n=48)$ of the patients who underwent shuntography showed clinical and radiographic signs of underdrainage prior to examination. Shuntography revealed mechanical complications of the VP shunt in $37 \%(n=18)$ as a cause of clinical deterioration and following revision operation. During shuntography, mechanical obstruction was discovered in $78 \%(n=14)$ and disconnection of shunt components in $22 \%(n=4)$. In the obstruction group, in 50\% $(n=7)$ the closure was detected in the ventricular catheter, in $29 \%(n=4)$ in the distal catheter of the VPS, and in $21 \%(n=3)$ in both sides of the VPS. In the case of an inconspicuous shuntography $(63 \%, n=31)$, the patients received symptomatic therapy $(32 \%, n=10)$ or re-adjustment of the valve setting $(68 \%, n=21)$. Fifty-seven percent of the patients who underwent surgical treatment improved clinically by at least one point according to the Kiefer score.

Conclusion Shuntography can produce valuable clinical information uncovering mechanic complications after implantation VPS in patients with idiopathic normal-pressure hydrocephalus. Patients with mechanical complications of their VPS needed revision surgery and showed clinical benefit after treatment.
\end{abstract}

Keywords Shuntography $\cdot$ Idiopathic normal-pressure hydrocephalus $\cdot$ Over-and underdrainage $\cdot$ Kiefer score

\section{Background}

Idiopathic normal pressure hydrocephalus (iNPH) of the elderly remains an enigmatic disease. Internal cerebrospinal fluid (CSF) diversion is established as the standard therapy, but in cases of poor outcome after ventriculoperitoneal shunting (VPS) or secondary deterioration, it can be difficult to differentiate between non-responders and patients with mechanical shunt dysfunction $[1,14]$. Thus, every neurosurgeon is familiar with the trade-off between wait and
Sergej Rot
sergej.rot@rambler.ru
Leonie Goelz
Leonie.Goelz@ukb.de
Holger Arndt
Holger.Arndt@ukb.de
Pawel Gutowski
pgut15@aol.com
Ullrich Meier
Johannes.Lemcke@ukb.de
Johannes Lemcke

Johannes.Lemcke@ukb.de

1 Department of Neurosurgery, Unfallkrankenhaus Berlin, Warener Str. 7, 12683 Berlin, Germany

2 Institute of Radiology and Neuroradiology, Unfallkrankenhaus Berlin, Warener Str. 7, 12683 Berlin, Germany

3 Department of Neurosurgery, Brodno Masovian Hospital, Warsaw Postgraduate Medical Centre, Warsaw, Poland 
see, non-invasive diagnostics, invasive functional diagnostics, or even revision surgery. Sufficient diversion of CSF is the main task of the VPS in the management of the disease "hydrocephalus." In well-functioning VPS therapies, the clinical symptoms of iNPH such as gait disturbance, shortterm memory disorder, and incontinence (Hakim triad), but also headaches and dizziness, are potentially reversible $[5$, $11,16]$. Several types of shunts are available but those with abdominal lead are implanted most often. Typically, the VPS consists of three components: the proximal catheter (ventricular catheter), shunt valve, and the distal catheter (abdominal drainage tube). All of these segments of the shunt may interfere with the viability of the VPS due to obstruction or disconnection which can lead to a complete failure. As a result, under-drainage of CSF may occur in the case of obstruction with clinical deterioration of gait disturbance or incontinence, or over drainage in disconnection with the leading symptom of headache [21]. Several studies have shown that more than $30 \%$ of patients with normal pressure hydrocephalus develop a mechanical complication due to obstruction of the VPS during the first year after shunt implantation [26, 27]. Only half of the newly implanted VPS function adequately during the second year, and less than one third works until the tenth year without revision. Clinical symptoms as well as assessments of internal and external CSF spaces on cranial imaging can signal shunt dysfunctions. However, these signs are not specific for mechanical complications in the course of the VPS therapy. In cases when the cause of a patient's clinical worsening is not evident, functional contrast-enhanced shuntography may be helpful [30]. Mirfakhraee first described contrast mediumassisted shuntography in 1985 [19]. However, literature on experiences with shuntography is scant and mainly consists of studies with small case numbers. There are no guidelines for shuntography nor protocols for the procedure or consensus on image interpretation, which severely limits its' clinical validity. This retrospective cohort study aimed to analyze contrast-enhanced shuntography by a quantitative method and to evaluate its' clinical value for decision-making in patients with suspected VPS dysfunction. In addition, this study elaborates on a workflow for indicating, conducting, and interpreting shuntographies.

\section{Materials and methods}

This retrospective cohort study included a total of 49 patients with iNPH who underwent ventriculoperitoneal shunting in an urban center of maximum care between 2000 and 2020 . All patients showed secondary clinical worsening suspicious of mechanical complications of the VPS. Clinical symptoms of the patients, change of ventricular width on follow-up cranial imaging, and obstruction or disconnection of the VPS documented by shuntography were analyzed. The need for revision operations or for changes of the valve-pressure settings was also recorded (Fig. 1). Kiefer score was used as a good clinical outcome parameter and was recorded before shuntography and subsequent specific treatment [13].

\section{Protocol of conducting shuntography}

Prior to shuntography in suspected mechanical complications of the VPS, the patient is hospitalized and a blood sample is drawn to exclude coagulopathies and relevant infections. A cranial CT scan is performed to evaluate ventricular width pre-interventionally. Additionally, a plain radiograph of the cranium, of the thorax, and the abdomen including the valve target image is acquired in order to detect possible disconnection in the shunt path. Just above the burr-hole reservoir, the hair is shaved to enable adequate soaking of the skin with a $7.5 \%$ iodinated solution (Braunovidon ${ }^{\circledR}$ ) approximately $20 \mathrm{~min}$ before the procedure for local disinfection. The examination takes place in an angiography suit in supine position. At first fluoroscopy images of shunt system from the ventricular catheter to the retroauricular region which harbors the valve and gravitational unit in posterior-anterior projection. After removal of the swab, the burr-hole reservoir is covered with an incision drape and the skin is disinfected again. Then, the silicone membrane of the burr-hole reservoir is punctured with an $18 \mathrm{G}$ butterfly needle and CSF is aspirated to test the patency of the ventricular catheter. Local anesthesia is not necessary, as patients tolerate the puncture of the borehole reservoir very well. In some cases, local anesthesia with EMLA plaster is used. If CSF can be aspirated, a quantity of approx. $10 \mathrm{ml}$ is sent out for microbiological and chemical examination. Afterwards, a syringe with $10 \mathrm{ml}$ of contrast medium for intrathecal application (Imeron M, containing Iodine) is connected to the butterfly and the needle is positioned into the direction of the ventricular catheter. Under fluoroscopy, a small amount (about 1-2 ml) of contrast medium is applied to visualize the patency of the ventricular catheter and to exclude a subgaleal leakage. The injection jet of the contrast medium through the openings at the sides and tip of the ventricular catheter in the direction of the lateral ventricles can be described. Then, the needle is diverted towards the valve and distal tube to trigger a distal flow towards the valve. The distal flow can be supported by changing the patient into a $30^{\circ}$ tilted position. Only small bolus of the contrast medium (about $1 \mathrm{ml}$ ) is injected to see if the contrast medium column reaches the valve and then the gravitational unit. If the valve and gravitational unit are contrasted, the drainage of the contrast medium through the distal catheter is followed under fluoroscopy in a posterior-anterior projection. During fluoroscopy, the system is also checked for continuity to the abdomen. Here the tip of the distal catheter is magnified 
Fig. 1 Flow diagram of decision processes after shuntography. Local revision surgery is the surgical revision of only one component of the VPS: ventricular, or abdominal catheter or valve

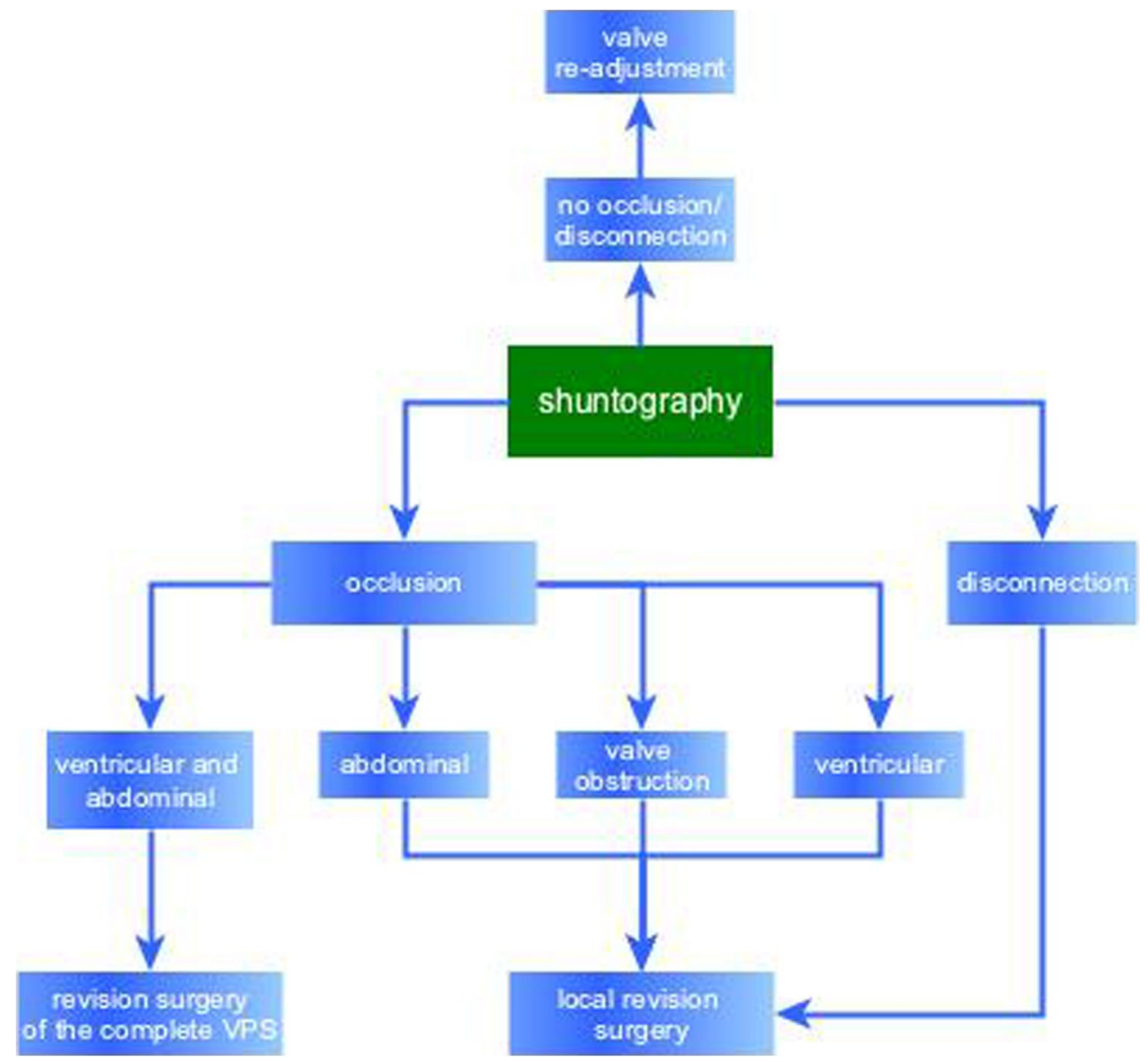

to observe a corresponding jet phenomenon of the contrast medium. In obese patients and meteorism, it can be challenging to visualize the contrast medium at the distal end of the catheter which can be overcome by increasing the radiation dose and contrast media bolus. Once the total of $10 \mathrm{ml}$ contrast agent is applied, isotonic saline solution bolus is used to push the contrast medium column distally. At last, the amount of contrast agent and saline solution applied is aspirated and discarded. The needle is removed and the puncture site is covered with a sterile band-aid. After the examination, the patient stays in bed in $30^{\circ}$ elevated upper body position for at least half an hour.

\section{Experimental shuntography in a patient model}

An experimental patient model was established to determine the minimal amount of contrast medium needed to prevent an increase in intracranial pressure during shuntography (Fig. 2A). The experimental setup consists of color balloons which simulate a head and neck region, ventricular system, and intestinal loops of a patient (Fig. 2A-C). Again, fluoroscopy images the ventricular catheter, the simulated ventricular system, and the valve with the gravitational unit in posterioranterior projection (Fig. 2D). The burr-hole reservoir is punctured and the contrast medium is applied into the ventricular system until the distal flow of the contrast medium towards the valve the contrast medium the contrast medium column can be tracked to the tip of the distal catheter until the abdominal contrast medium jet becomes visible (Fig. 2E). In summary, experimental simulation of shuntography showed it required only 2-3 ml of contrast medium for and adequate visualization of a VPS. In the clinical setting, $3 \mathrm{ml}$ marks the amount of contrast medium required under ideal conditions. According to our experience in the majority of cases, $5 \mathrm{ml}$ of contrast medium is needed but as described above shuntography in obese patients can require up to $10 \mathrm{ml}$ of contrast medium.

\section{Clinical case examples}

Table 1 shows the examples of NPH patients with clinical suspicion of a mechanical complication in the VPS, which can be visualized by a shuntogram (Fig. 3). 
Fig. 2 Experimental model of a shuntography. A Experimental setup, the model is placed on angiography stage. B Yellow balloon: simulation of the head and neck region. Red, heartshaped balloon: simulation of the ventricular system. The balloon is filled with water and has an inserted ventricular catheter. C Blue children's bathtub is half filled with water: simulation of the abdomen. Color balloons: simulation of the intestinal loops. The distal catheter is lowered into the bath tub under the water filled balloons. D After injection of Imeron M radiographic image shows contrasting of the ventricular system. $\mathbf{E}$ Radiographic image shows distal flow of the contrast medium along the distal catheter
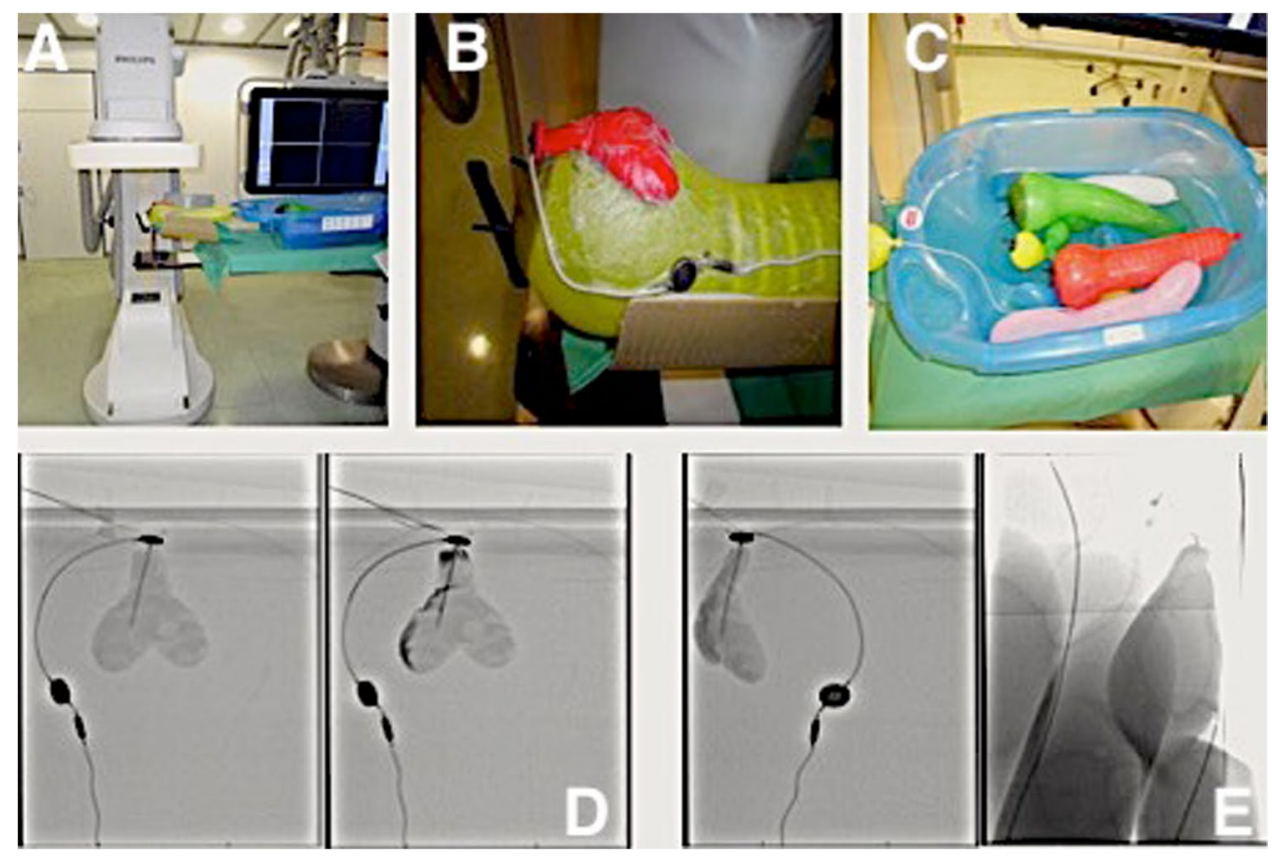

Table 1 Shuntographies of patients with shunt dysfunction

\begin{tabular}{|c|c|c|}
\hline $\mathrm{X}$-ray picture & Pathology designation & Description \\
\hline A & Obstruction of proximal catheter & $\begin{array}{l}\text { White arrow: butterfly needle placed in the prechamber, proximal catheter } \\
\text { and ventricular catheter show typical double contour as a sign of pas- } \\
\text { sage disruption of the contrast medium; } \\
\text { Black arrow: medium contrasted proGAV and gravitational unit including } \\
\text { a visible part of distal catheter }\end{array}$ \\
\hline B & Obstruction of the valve (proGAV/gravitational unit) & $\begin{array}{l}\text { Black arrow: typical double contour of the connecting catheter between } \\
\text { prechamber and Codmann Hackim valve as a sign of passage disruption } \\
\text { of the contrast medium; } \\
\text { White arrow: free passage of the contrast medium along the perforations } \\
\text { of the ventricular catheter with particularly visible contrast medium in } \\
\text { the right ventricle }\end{array}$ \\
\hline $\mathrm{C}$ & Obstruction of abdominal catheter & $\begin{array}{l}\text { White arrow: passage break of the contrast medium; } \\
\text { Black arrow: no release of contrast medium at the distal end of the cath- } \\
\text { eter, typical double contour of the non-contrasted catheter }\end{array}$ \\
\hline $\mathrm{D}$ & A non-obstructed abdominal catheter (normal finding) & $\begin{array}{l}\text { White arrow: release of the contrast medium from the tip of the abdomi- } \\
\text { nal catheter } \\
\text { Black arrow: spread of the contrast medium along the intestinal loops }\end{array}$ \\
\hline
\end{tabular}

\section{Statistics}

Numerical variables were expressed as mean \pm standard deviation and categorical variables as percentages using Microsoft Excel for Mac (Microsoft Corp.).

\section{Results}

Around 80 patients with NPH are treated in our clinic every year. Between 2000 and 2020, 49 patients with NPH underwent shuntography in our hospital. The median age of $53.1 \%$ male and $46.9 \%$ female patients was $66.2 \pm 17.1$ years (median, 70 years, age range, 54-93 years). The following valve types were used in patients, selected for the present study: proGAV, GAV, dual-switch, NMT (Miethke), Codmann-Hackim valve, OSV II (Integra). Ninety-eight percent $(n=48)$ of patients showed symptoms of under-drainage and $2 \%$ of them $(n=1)$ symptoms of over-drainage clinically and radiographically. Shuntography revealed mechanical complications of the VP shunt in 37\% $(n=18)$ of cases as a cause of clinical deterioration. The cause of dysfunction in the shunt system was either obstruction or disconnection. Disconnection of the shunt system in the patient group with mechanical complications $(n=18)$ was discovered in $22 \%(n=4)$. The radiological evaluations of shuntographies in patients who 
Fig. 3 Clinical examples of radiographic imaging of shunt dysfunction (description in Table 1)
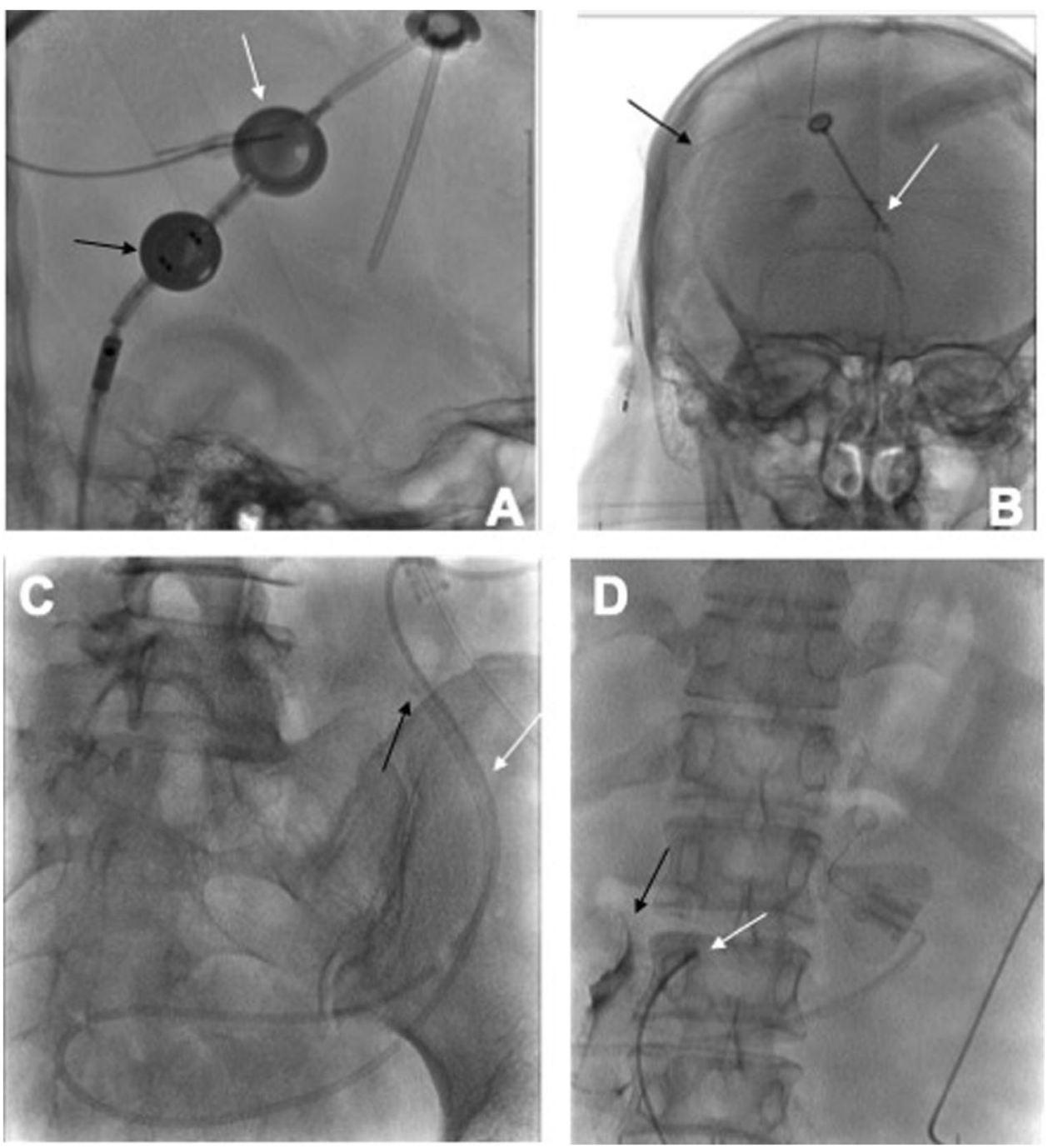

were advised to undergo revision surgery due to obstruction or disconnection of VPS were confirmed intraoperatively. Radiological evaluations were correct in all cases. Obstruction of the VPS was discovered in $78 \%(n=14)$ of all mechanical complications $(n=18)$ and occurred at all parts of the VPS. In $50 \%(n=7)$ of the cases, obstruction was detected in the ventricular catheter and in 29\% $(n=4)$ in the distal catheter of the VPS. In $21 \%(n=3)$ of cases, obstruction was found both in the ventricular and distal catheter of the VPS. A typical localized site or cause for obstruction of the shunt could not be determined in this study.

In the case of an inconspicuous shuntography (63\%, $n=31$ ) meaning in the case of evidence of neither obstruction nor disconnection of the VPS, the patients either received symptomatic therapy $(32 \%, n=10)$ or re-adjustment of the valve setting $(68 \%, n=21)$. The adaptation of the valve setting was patient-specific: in patients with headaches and rather narrow lateral ventricles, opening pressure of the low-pressure valve was increased; in patients with deterioration of gait disturbance expansion of internal CSF spaces, opening pressure was decreased.

Symptomatic therapy consisted of medication against headaches and dizziness as well as physiotherapeutic cotreatment to improve gait disturbance. Three months after surgical and conservative therapy, patients were followed up in the neurosurgical department. The Kiefer score served primary parameter for clinical evaluation of the patients. More than half of the patients (57\%) improved clinically after revision surgery (reduction in Kiefer score by at least one point, Fig. 4, gray bars). In the conservative group, clinical symptoms were unchanged in $70 \%$ of the cases (Fig. 4, pink bars). An improvement of gait pattern was observed in $24 \%$ of all patients, headaches improved in $8 \%$, and dizziness, mnestic disorder, and urinary incontinence each in $2 \%$ of cases (not shown graphically).

One of the 49 patients showed an infection of the VPS with skin flora (Staphylococcus epidermidis) after non-pathologic shuntography leading to subsequent explantation of 
Fig. 4 Clinical outcome after conservative and surgical treatment

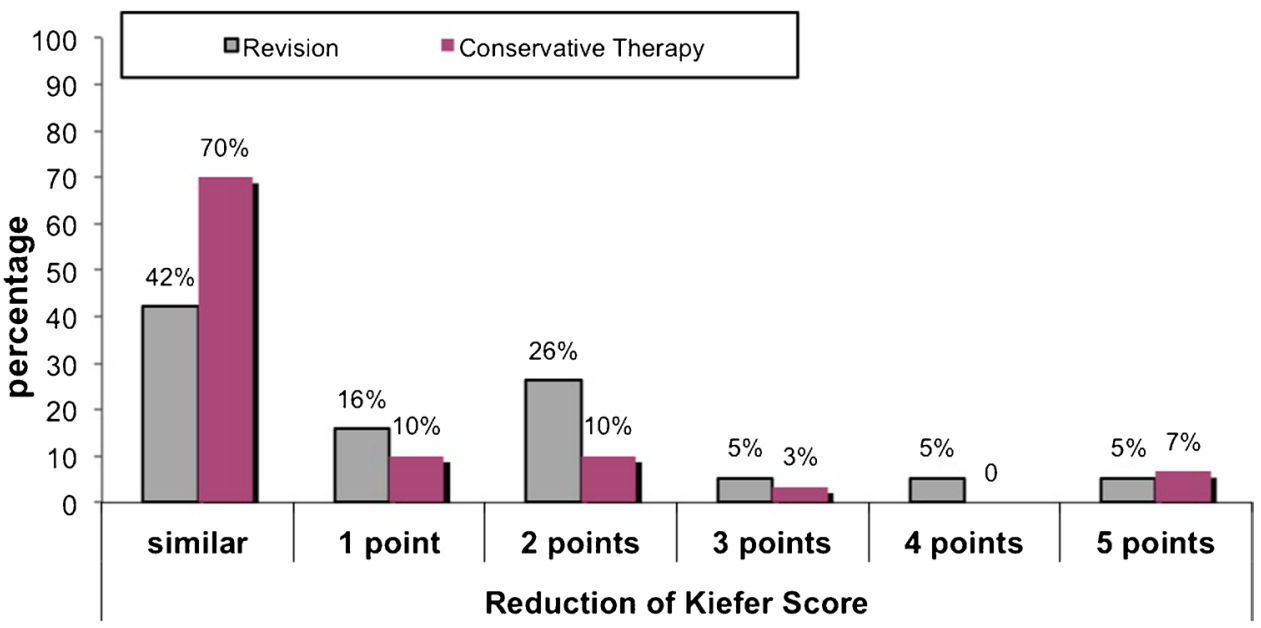

the whole system. Thus, the complication rate of shuntography was $2 \%$.

\section{Discussion}

Diagnosing a shunt malfunctions is a challenge. The incidences of shunt obstructions after implantations of a VPS increase over time [31]. In contrast to previous studies, the present study identified obstruction of the VPS as a major mechanical complication in patients with normal pressure hydrocephalus. Subclinical infections of the CNS and as a result increased protein contents with higher viscosity might be a reason for obstruction of the shunts. Other causes could be material failures such as defective valves and subclinical minor peritoneal inflammations with occlusion of the distal catheter. All the more it was important to establish an elegant, minimally invasive, and safe method for diagnosing shunt dysfunctions in this patient population. In an experienced team of neurosurgeons and radiologists, shuntographies take only about $15 \mathrm{~min}$ in clinical practice. The low infection rate and the straight-forward information in cases of obstructed or disconnected VPS profile speak in favor of contrastenhanced shuntography. The high level of reliability of contrast-enhanced shuntography suggests that this simple method provides clinically reliable information about the patency of shunt systems [30]. Neurosurgical follow-up is essential to determine if and why a patient's clinical condition deteriorates after shunt placement in patients with iNPH [11]. According to the present study in almost every fourth patient a pathological shuntogram with signs of a mechanical complication can be anticipated. This result is of great importance for strict follow-up and management of these patients who always need surgical therapy [3]. So far contrast-enhanced shuntography is standard of care in every neurosurgical clinic. Doctors might avoid to use this method because of their lack of experience. If mechanical shunt dysfunction is suspected, the VPS can be visualized on plain radiographs to exclude disconnections; obstructions can therefore not be detected. The most common consequence of such diagnostics is the replacement of the complete VPS. Shuntography also allows selective visualization of the location of a potential mechanical problem in the path of the VPS. This is a major advantage of this diagnostic procedure, since it is not always necessary to replace an entire VPS system, but only its "defective" part. The present work showed that about $60 \%$ of the patients would be exposed to unnecessary revision surgeries and associated complications. Other studies evaluating unnecessarily revised VPS systems do not exist at this time. On average shunt infections occur in up to $8 \%$ of cases. Shunt infections are always a definitive reason for revision surgery [7, 22]. However, literature also reports infection rates of up to $12 \%$, especially in combination of shunt exposure and intraoperative functional testing of the shunt in cases of suspected mechanical complications [6]. The latter approach is a widely used method. Contrast-enhanced shuntography however is a simple and effective method with a low-infection rate ( $2 \%$ of cases) to assess the patency of VPS in patients with normal-pressure hydrocephalus and suspected mechanical complications [2, 30]. Therefore, it seems advisable to carry out a contrast agent-assisted shuntography before any revision surgery in order to localize mechanical problems more accurately and thus reduce the duration of revision surgeries and postoperative infection rates. In contrast to an alternative method of using radionuclides for shuntography, contrast-enhanced shunt imaging shows better spatial-temporal resolution, allowing focused local surgical revision $[4,15,20,26,30]$. In our collective clinical outcome of those patients after revision surgery due to a pathological shuntogram and those patients after conservative therapy due to an inconspicuous shuntogram showed no significant 
difference. On the one hand, this could be attributed to the relatively small number of cases for sufficient statistical evaluation. On the other hand, surgical elimination of the obstruction in the shunt system is only one side of the coin. Complementary treatment of patients postoperatively (physiotherapy, educational measures, supportive medication) as well as close neurosurgical follow-up is probably just as important and the fundaments during exclusively conservative therapies in patients with persisting or recurrent symptoms after VPS placement.

\section{Limitations}

The present study has certain limitations. Some patients' records were incomplete which significantly reduced the number of included patients. In addition, the study includes patients with idiopathic normal pressure hydrocephalus which were treated with various valve types. Initial valve settings, onset and duration of symptoms, and the time between implantation of the VPS and shuntography are heterogenous in this retrospective cohort study.

\section{Conclusion}

Contrast-enhanced shuntography is a safe and reliable clinical method for the diagnosis of mechanical shunt complications in patients with normal-pressure hydrocephalus. More than $50 \%$ of patients benefit from revision surgeries triggered by pathological shuntograms which identified the causes of mechanical shunt complications early and selectively.

Acknowledgements Not applicable.

Author contribution Sergej Rot collected, analyzed, and interpreted equally the datasets. Sergej Rot created all the graphs presented here. Sergej Rot was the main contributor in writing the presented manuscript. Leonie Goelz and Holger Arndt interpreted the radiologic scans and revised the manuscript. Johannes Lemcke, Pawel Gutowski, and Ullrich Meier planned the study and revised the manuscript. All authors read and approved the final manuscript.

Funding Open Access funding enabled and organized by Projekt DEAL. Neither the authors nor the institution received funding for the submitted research.

\section{Declarations}

Conflict of interest We declare that we have no conflict of interest.

Ethical approval and consent to participate All procedures performed in studies involving human participants were in accordance with the ethical standards of the institutional and hospital committee
(Unfallkrankenhaus Berlin) and with the 1964 Helsinki declaration and its later amendments or comparable ethical standards. For this type of study formal consent is not required.

Open Access This article is licensed under a Creative Commons Attribution 4.0 International License, which permits use, sharing, adaptation, distribution and reproduction in any medium or format, as long as you give appropriate credit to the original author(s) and the source, provide a link to the Creative Commons licence, and indicate if changes were made. The images or other third party material in this article are included in the article's Creative Commons licence, unless indicated otherwise in a credit line to the material. If material is not included in the article's Creative Commons licence and your intended use is not permitted by statutory regulation or exceeds the permitted use, you will need to obtain permission directly from the copyright holder. To view a copy of this licence, visit http://creativecommons.org/licenses/by/4.0/.

\section{References}

1. Aschoff A, Kremer P, Hashemi B, Kunze S (1999) The scientific history of hydrocephalus and its treatment. Neurosurg Rev 22(2-3):67-93

2. Benzel EC, Mirfakhraee M, Hadden TA (1991) Evaluation of CSF shunt function: value of functional examination with contrast material. AJNR 12(1):143-147

3. Bergsneider M, Black PM, Klinge P, Marmarou A, Relkin N (2005) Surgical management of idiopathic normal-pressure hydrocephalus. Neurosurgery 57(3 Suppl):S29-39

4. Blair K, AuCoin R, Kloiber R, Molnar CP (1989) The complementary role of plain radiographs and radionuclide shuntography in evaluating CSF-VP shunts. Clin Nucl Med 14(2):121-123

5. Bradley WG Jr (2015) CSF flow in the brain in the context of normal pressure hydrocephalus. AJNR 36:831-838

6. Erol FS, Ozturk S, Akgun B, Kaplan M (2017) Ventriculoperitoneal shunt malfunction caused by fractures and disconnections over 10 years of follow-up. ChNS 33(3):475-481

7. Feletti A, d'Avella D et al (2019) Ventriculoperitoneal shunt complications in the European Idiopathic Normal Pressure Hydrocephalus Multicenter Study. Oper Neurosurg (Hagerstown) 17(1):97-102

8. Greitz D (1993) Cerebrospinal fluid circulation and associated intracranial dynamics. A radiologic investigation using MR imaging and radionuclide cisternography. Acta Radiol Suppl 386:1-23

9. Hakim S, Adams RD (1965) The special clinical problem of symptomatic hydrocephalus with normal cerebrospinal fluid pressure. Observations on cerebrospinal fluid hydrodynamics. J Neurol Sci 2(4):307-27

10. Hiraoka K, Meguro K, Mori E (2008) Prevalence of idiopathic normal-pressure hydrocephalus in the elderly population of a Japanese rural community. Neurol Med Chir (Tokyo) 48(5):197-99 (discussion 9-200)

11. Kazui H, Mori E, Ohkawa S, Okada T, Kondo T, Sakakibara R et al (2013) Predictors of the disappearance of triad symptoms in patients with idiopathic normal pressure hydrocephalus after shunt surgery. J Neurol Sci 328(1-2):64-69

12. Khan QU, Wharen RE, Grewal SS, Thomas CS, Deen HG Jr, Reimer R et al (2013) Overdrainage shunt complications in idiopathic normal-pressure hydrocephalus and lumbar puncture opening pressure. Journal Neurosurg 119(6):1498-1502

13. Kiefer M, Eymann R et al (2003) A grading system for chronic hydrocephalus. Zentralbl Neurochir 64(3):109-115 
14. Kiefer M, Unterberg A (2012) The differential diagnosis and treatment of normal-pressure hydrocephalus. Dtsch Arztebl Int 109:15-25

15. May CH, Aurisch R, Kornrumpf D, Vogel S (1999) Evaluation of shunt function in hydrocephalic patients with the radionuclide 99mTc-pertechnetate. ChNS 15(5):239-44 (discussion 245)

16. McGirt MJ, Woodworth G, Coon AL, Thomas G, Williams MA, Rigamonti D (2008) Diagnosis, treatment, and analysis of longterm outcomes in idiopathic normal-pressure hydrocephalus. Neurosurgery 62(Suppl 2):670-677

17. Meier U, Konig A, Miethke C (2004) Predictors of outcome in patients with normal-pressure hydrocephalus. Eur Neurol 51(2):59-67

18. Meier U, Stengel D, Muller C, Fritsch MJ, Kehler U, Langer N et al (2013) Predictors of subsequent overdrainage and clinical outcomes after ventriculoperitoneal shunting for idiopathic normal pressure hydrocephalus. Neurosurgery 73(6):1054-1060

19. Mirfakhraee M et al (1985) Metrizamide shuntography for evaluation of shunt malfunction in hydrocephalus. AJNR 6(5):815-822

20. O'Brien DF, Taylor M, Park TS et al (2003) A critical analysis of 'normal' radionucleotide shuntograms in patients subsequently requiring surgery. ChNS 19:337-341

21. Oi S (2010) Hydrocephalus research update-controversies in definition and classification of hydrocephalus. Neurol Med Chir (Tokyo) 50:859-869

22. Park MK et al (2015) A retrospective analysis of ventriculoperitoneal shunt revision cases of a single institute. J Korean Neurosurg Soc 57(5):359-363

23. Piatt JH Jr, Carlson CV (1993) A search for determinants of cerebrospinal fluid shunt survival: retrospective analysis of a 14-year institutional experience. Pediatr Neurosurg 19:233-241
24. Poca MA, Solana E, Martinez-Ricarte FR, Romero M, Gandara D, Sahuquillo J (2012) Idiopathic normal pressure hydrocephalus: results of a prospective cohort of 236 shunted patients. Acta Neurochir Suppl 114:247-253

25. Preuss M, Hoffmann KT, Reiss-Zimmermann M, Hirsch W, Merkenschlager A, Meixensberger J et al (2013) Updated physiology and pathophysiology of CSF circulation - the pulsatile vector theory. ChNS 29(10):1811-1825

26. Thompson EM, Wagner K, Kronfeld K et al (2014) Using a 2 -variable method in radionuclide shuntography to predict shunt patency. J Neurosurg 121:1504-1507

27. Torsnes L, Blåfjelldal V, Poulsen FR (2014) Treatment and clinical outcome in patients with idiopathic normal pressure hydrocephalus - a systematic review. Dan Med J 61:A4911

28. Vanneste JA (2000) Diagnosis and management of normal-pressure hydrocephalus. J Neurol 247(1):5-14

29. Vanneste J, Augustijn P, Dirven C, Tan WF, Goedhart ZD (1992) Shunting normal- pressure hydrocephalus: do the benefits outweigh the risks? A multicenter study and literature review. Neurology 42(1):54-59

30. von Eckardstein KL et al (2017) Contrast-enhanced shunt series ("shuntography") compare favorably to other shunt imaging modalities in detecting shunt occlusion. Acta Neurochir (Wien) 159(1):63-70

31. Wu Y, Green NL, Wrensch MR et al (2007) Ventriculoperitoneal shunt complications in California: 1990 to 2000. Neurosurgery 61:557-562

Publisher's note Springer Nature remains neutral with regard to jurisdictional claims in published maps and institutional affiliations. 